\title{
New, green and miniaturized analytical method for determination of cefadroxil monohydrate in capsules
}

\author{
Bianca Aparecida de Marco ${ }^{\mathrm{a}}$, Ana Carolina Kogawa*a ${ }^{\text {, Hérida Regina Nunes Salgado }}{ }^{\mathrm{a}}$ \\ ${ }^{a}$ São Paulo State University (UNESP), School of Pharmaceutical Sciences, Campus Araraquara, São Paulo, Brazil \\ *Corresponding author: ac_kogawa@uahoo.com.br
}

\begin{abstract}
Cefadroxil, an oral antimicrobial, presents few techniques optimized for the reduction of solvents and toxic residues and/or nonuse of them. So, a quantitative, new and miniaturized method for determination of cefadroxil monohydrate in capsules has been developed and validated by spectrophotometric method in the visible region according to the international guidelines. The analyzes were performed using microplates containing 96 wells, $1 \%$ of phenolphthalein and sodium hydroxide $0.1 \mathrm{M}$ as reagent at $552 \mathrm{~nm}$. The method was (i) linear in the range of $15-115 \mu \mathrm{g} \mathrm{mL}^{-1}$, (ii) selective when comparing standard, sample, adjuvants and color reagent, (iii) precise with deviations below $4 \%$, (iv) accurate when comparing the proposed method with the HPLC method, (v) robust by making small and deliberate modifications to the method, (vi) besides being fast, low cost, eco-friendly and generates minimal amount of waste. The method can be applied to the routine quality control of cefadroxil monohydrate in capsules and an effective and accessible alternative that contemplates the concepts of current and sustainable green analytical chemistry.
\end{abstract}

Keywords: cefadroxil monohydrate, capsules, spectrophotometric method in the visible region, miniaturized method, green analytical chemistry.

\section{Introduction}

Cefadroxil is a semi-synthetic antibiotic intended for oral administration and belongs to the first generation group of cephalosporins [1-2]. It has bactericidal activity by inhibiting the synthesis of the cell wall of the bacterium being used in the treatment of infections caused mainly by Gram-positive bactéria [3-7]. The drug is chemically known as (6R,7R)-7-[(2R)-2-amino-2-(4-hydroxyphenyl) acetyl amino]-3-methyl-8-oxo-5-tia-1 azabicyclo[4.2.0] oct-2-eno-2carboxilic acid [8].

Infections caused by microorganisms that are vulnerable to cefadroxil are common in society and reach a large part of the population. Due to the recurrent sale of this oral cephalosporin, studies become fundamental, mainly on quality control, which involves research and development of highly relevant analytical methods for the optimization of the analyzes in the industries and the guarantee of the quality of the already commercialized product [9-10].

Although there are several studies in the literature for the development of analytical methods for the identification and quantification of cefadroxil, there are few techniques optimized for the reduction of solvents and toxic residues and/or non-use of them. It is of utmost importance to replace analytical methods considered harmful to the environment and operators, by efficient and safe methods that present a significant reduction of the use of organic solvents, cost and energy expenditure for the industries [11].

So, a miniaturized spectrophotometric method in the region visible using microplate was chosen to quantify and identify the cefadroxil monohydrate in capsules.

\section{Experimental}

Materials
The standard was cefadroxil monohydrate (purity 93.03\%) and the samples were cefadroxil monohydrate $500 \mathrm{mg}$ capsules. They were kindly supplied by EMS pharmaceutical company (Hortolândia, SP, Brazil).

Adjuvants present in the capsules of cefadroxil (magnesium stearate, croscarmellose sodium and talc) were kindly supplied by Pharmacotechnic Laboratory of the School of Pharmaceutical Sciences from São Paulo State University (UNESP).

Reagents (phenolphthalein, analytical grade - Synth® - and sodium hydroxide, analytical grade - Dinâmica $\left.{ }^{\circledR}\right)$ were obtained and prepared by the Quality Control Laboratory of the School of Pharmaceutical Sciences from São Paulo State University (UNESP).

\section{Spectrophotometric conditions}

The UV-Visible spectrophotometer used was the model SPECTRO star® Nano (BMG LabTech, Germany) and a 96-well microplate was used for measuring absorbance at a wavelength of $552 \mathrm{~nm}$. The software used as support for construction the calibration curves was Microsoft Excel (2010).

\section{Solutions}

\section{Preparation of cefadroxil standard}

An equivalent of $10 \mathrm{mg}$ cefadroxil standard was weighed and transferred to a $10 \mathrm{~mL}$ volumetric flask and the volume was completed with ultrapure water, in order to obtain a stock solution of $1000 \mu \mathrm{g} \mathrm{mL}^{-1}$. Aliquots of $75,175,275$, 375,475 and $575 \mu \mathrm{L}$ of this solution were transferred to 5 $\mathrm{mL}$ volumetric flasks, and the volumes were completed with ultrapure water, in order to obtain working solutions of 15 , $35,55,75,95$ and $115 \mu \mathrm{g} \mathrm{mL}$, respectively. All the solutions were prepared in triplicate. 


\section{Preparation of cefadroxil sample}

After accurate weighing of twenty capsules of cefadroxil monohydrate, an equivalente of $10 \mathrm{mg}$ cefadroxil was weighed and transferred to a $10 \mathrm{~mL}$ volumetric flask and the volume was completed with ultrapure water, in order to obtain a stock solution of $1000 \mu \mathrm{g} \mathrm{mL} \mathrm{m}^{-1}$. Without the filtration step, aliquots of $75,175,275,375,475$ and $575 \mu \mathrm{L}$ of this solution were transferred to $5 \mathrm{~mL}$ volumetric flasks, and the volumes were completed with ultrapure water, in order to obtain working solutions with a concentrations of $15,35,55,75,95$ and $115 \mu \mathrm{g} \mathrm{mL} \mathrm{m}^{-1}$. All the solutions were prepared in triplicate.

\section{Preparation of adjuvants solution}

A mixture of adjuvants (magnesium stearate, croscarmellose sodium and talc) present in the sample of capsules was prepared in laboratory using amounts of pharmaceutical grade in accordance with the production of the formulation of cefadroxil monohydrate $500 \mathrm{mg}$ capsules. Stock adjuvants solution was prepared in the same way as the cefadroxil standard and sample to evaluate the interference of the adjuvants in the method.

\section{Preparation of color reagent}

The reagents used to development and validation of this method were phenolphthalein and sodium hydroxide $(\mathrm{NaOH})$, analytical grade. Other reagents were tested, such as ascorbic acid $3 \%$, methyl red $0.1 \%$ and bromothymol blue $1 \%$ However, phenolphthalein $1 \%$ and $\mathrm{NaOH} 0.1 \mathrm{M}$ was the only one that interacted with the cefadroxil molecule. Several concentrations of this dye were performed and the combination of $800 \mu \mathrm{L}$ of phenolphthalein $1 \%$ and $400 \mu \mathrm{L}$ of $\mathrm{NaOH} 0.1 \mathrm{M}$ in a $25 \mathrm{~mL}$ volumetric flask (the volume was completed with ultrapure water) was the one that best interacted with the drug, presenting absorbances of 0.2 to 0.8 and linear correlation between them and drug concentrations, according to Lambert Beer's Law.

Phenolphthalein and $\mathrm{NaOH}$ solution were prepared using the molar mass, 318.32 and $40.00 \mathrm{~g} \mathrm{~mol}^{-1}$, respectively.

\section{Obtaining of analytical curve}

Solutions of $15,35,55,75,95$ and $115 \mu \mathrm{g} \mathrm{mL} \mathrm{m}^{-1}$ of cefadroxil standard were prepared using ultrapure water. Aliquots of $100 \mu \mathrm{L}$ of these solutions were added to the microplate and $100 \mu \mathrm{L}$ of the color reagent was added to each well contained working solutions. The absorbances were measured at $552 \mathrm{~nm}$, at shaking in time of 2 minutes with rotation of $500 \mathrm{rpm}$.

The stability of the color complex formed depends on the amount of drug present in the solution; the higher the amount of drug, the faster the loss of color and vice versa. For this reason, the stipulation of time is fundamental (including it was tested in the robustness parameter), in this case the chosen shaking time was 2 minutes.

\section{Method validation}

The quantification method was validated according by the following parameters: specificity, linearity, limits of detection (LOD) and quantification (LOQ), precision, accuracy and robustness. All carried out according to the International Conference on Harmonization (ICH) and US Food and Drug Administration (FDA) [12-13].

\section{Selectivity}

Selectivity of the method was determined by a mixture of the adjuvants (magnesium stearate, croscarmellose sodium and talc) present in the cefadroxil monohydrate capsules, to verify if the adjuvants would interfere in the quantification of cefadroxil using the proposed method. Solutions of the adjuvants with mass equivalent to the capsules were prepared for the determination of the spectrum.

\section{Linearity, Limits of Detection (LOD) and Limits of Quantitation}

Tree different calibration curves were constructedin triplicate and obtained on tree different days with six concentrations $\left(15,35,55,75,95\right.$ and $\left.115 \mu \mathrm{g} \mathrm{mL}{ }^{-1}\right)$ of cefadroxil standard. The linearity parameter was evaluated according to regression lines using least squares and ANOVA to calculate the calibration equation and correlation coefficient, and the standardized residual graph. The limits of detection and quantitation were obtained by the Equations 1 and 2 as described in the literature [12].

\section{Equation 1: LOD: $3.3 \sigma / \mathrm{S}$ Equation 2: LOQ: $10 \sigma / \mathrm{S}$}

Where: $\sigma$ : Standard deviation of the analytic curve intercept; $S$ : Average of the analytic curve slope

\section{Precision}

Three types of precision were evaluated in this method. The repeatability (intra-day precision) was performed by the preparation and reading of six differents solutions of cefadroxil standard at the concentration of $55 \mu \mathrm{g} \mathrm{mL}^{-1}$, on the same day, analyzing the RSD\% among such determinations; the intermediate (inter-day precision) was evaluated under the same conditions as above, on three different days and its statistical evaluation was based on the ANOVA single factor; and inter-analysts precision was performed by the preparation and reading of six differents solutions of cefadroxil standard at the concentration of 55 $\mu \mathrm{g} \mathrm{mL} \mathrm{m}^{-1}$, on the same day, but done by two different analysts, the statistical evaluation was based on the F-test (Snedecor) and $t$-test (Student).

\section{Accuracy}

The accuracy of the method was performed through a comparative analysis of the methods [12], in which the results obtained in this validation were compared with a second physicochemical method (High Performance Liquid Chromatography - HPLC) already validated for the drug, in which it presents similar concentrations worked on the linear curve [14]. The comparative assay was performed using cefadroxil sample solution. Six content analyzes were 
performed using HPLC and UV methods. The content was calculated by Equations 3 and 4 . The concentration used for both methods was $55 \mu \mathrm{g} \mathrm{mL} \mathrm{m}^{-1}$ and the statistical evaluation was performed through the F-test (Snedecor) and $t$-test (Student).

\section{Equation 3: $\mathrm{SC}=\mathrm{AS} \times \mathrm{CRS} \div \mathrm{ASR}$ \\ Equation 4: $\mathrm{SC} \%=\mathrm{SC} \times 100 \div \mathrm{Ct}$}

Where: $S C$ : sample concentration $\left(\mu \mathrm{g} \mathrm{mL}{ }^{-1}\right) ; A S$ : absorbance of the sample; CRS: concentration of the reference substance $\left(\mu \mathrm{g} \mathrm{mL}^{-1}\right) ; A S R$ : absorbance of reference substance; $C t$ : theoretical concentration of the sample ( $\mu \mathrm{g}$ $\mathrm{mL}^{-1}$ )

\section{Robustness}

The robustness of the method was evaluate through three parameters varied independently: wavelength (554 and 550 $\mathrm{nm}$ ); source of deionized water (two different laboratories) and shaking time (180 and 60 seconds). The results obtained by varying this parameter were analyzed by F-test (Snedecor) and $t$-test (Student).

\section{Results}

\section{Method Validation}

\section{Selectivity}

The selectivity of the method was proven because the adjuvants present in the cefadroxil monohydrate capsules did not interfere in the quantification and identification of the drug.

Figure 1 allow to verify that color reagent containing $1 \%$ phenolphthalein and $\mathrm{NaOH} 0.1 \mathrm{M}$ reacts with the drug molecule resulting in a decrease in absorbance as the drug concentrations increase, exhibiting likewise that the adjuvants do not react with the color reagent in the same way as the drug, which prover their non-interference in the quantification of cefadroxil.

The mechanism of the method was based on the acid-base reaction. The cefadroxil has an acid character and by including a reagent with a basic character and a dye it was possible to establish a relation of the amount of drug with the observed color of the solution. The higher the amount of cefadroxil, the more drug available for reaction and the weaker the color of the solution after 2 minutes of reaction. The lower the amount of cefadroxil, the less drug available for reaction and the more intense the color of the solution after 2 minutes of reaction.

\section{Linearity, Limits of Detection (LOD) and Limits of Quantitation}

The analytical curve for the cefadroxil standard was derived from the mean values of the absorbances with respect to the concentrations from 15 to $115 \mu \mathrm{g} \mathrm{mL}^{-1}$, as shown in Figure 2. The analysis of the significance of the regression is represented by Table 1 and the standardized residual graph is found in Figure 2.
The method presented linear with correlation coefficient (r) of 0.9996 and the statistical data showed no significant linearity deviation at a $5 \%$ level of variance, with $\mathrm{F}_{\text {calculated }}$ (0.04) lower than the $F_{\text {critical }}$ (3.26). Limits of detection and quantification were calculated to determine the sensitivity of the method. The value found for the detection limit was 1.67 $\mu \mathrm{g} \mathrm{mL}^{-1}$, and the limit of quantification was $5.07 \mu \mathrm{g} \mathrm{mL}^{-1}$.
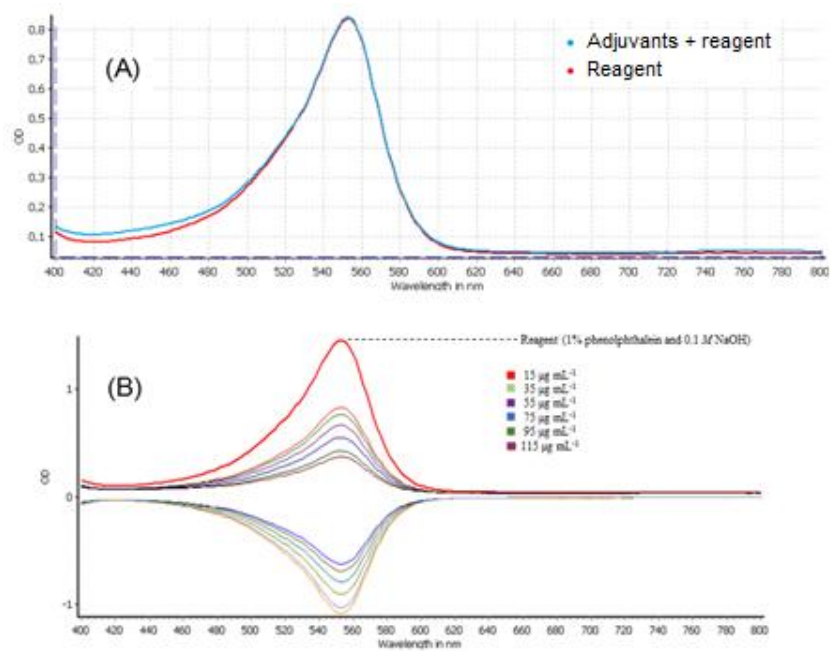

Figure 1. Evaluation of the selectivity of the method. (A) Spectrum exhibiting no interference of the adjuvants with the reagent and (B) spectrum exhibiting the reaction of the reagent with the cefadroxil.

Table 1. Variance analysis of the absorbance values used to construct the analytical curve of the cefadroxil monohydrate by spectrophotometric method

\begin{tabular}{cccccc}
\hline $\begin{array}{c}\text { Sources of } \\
\text { variation }\end{array}$ & $\begin{array}{c}\text { Degrees } \\
\text { of } \\
\text { freedom }\end{array}$ & $\begin{array}{c}\text { Sum of } \\
\text { squares }\end{array}$ & Variance & $\mathbf{F}_{\text {calculated }}$ & $\mathbf{F}_{\text {critical }}$ \\
\hline $\begin{array}{c}\text { Between } \\
\text { concentration }\end{array}$ & 5 & 0.50799 & 0.10160 & $278.94^{*}$ & 3.11 \\
$\begin{array}{c}\text { Linear } \\
\text { regression }\end{array}$ & 1 & 0.50711 & 0.50711 & $\begin{array}{c}1393.44 \\
*\end{array}$ & 4.75 \\
$\begin{array}{c}\text { Linearity } \\
\text { deviations }\end{array}$ & 4 & 0.00088 & 0.0002205 & 0.32 & 3.26 \\
Residue & 12 & 0.00437 & 0.0003642 & --- & -- \\
Total & 17 & 0.51236 & --- & -- & -- \\
\hline
\end{tabular}
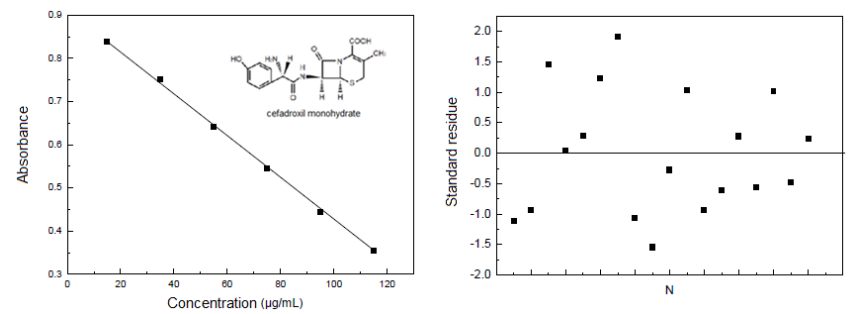

Figure 2. (A) Analytical curve of the cefadroxil monohydrate by spectrofotometric method. (B) Residual graph for the analysis of the linearity of the spectrophotometric method. 


\section{Precision}

The results obtained in the statistical analyzes are presented in Table 2. The precision parameter was in accordance with the acceptance criteria defined in international guidelines [12-13]. The analysis of intra-day precision showed a relative standard deviation less than $3 \%$. The analysis of variance of the values of the inter-day precision showed $F_{\text {calculado }}$ (1.52) less than $F_{\text {critical }}$ (3.11). The inter-analyst precision was proved by the F-test (Snedecor) and t-test (Student), in which $\mathrm{t}_{\text {calculated }}(0.29)$ was less than $\mathrm{t}_{\text {critical }}(2.23)$.
Accuracy

The results of the accuracy by content determination performed through the comparison between methods are presented in Table 3. The tests were performed by the spectrophotometric and chromatographic techniques with the same theoretical values of concentrations, resulting in values of sample contents of the cefadroxil monohydrate capsules of $99.95 \%$ and $99.82 \%$, respectively. The statistical comparison of the content values found by the two methods was performed by the ttest (Student). The $t_{\text {calculated }}$ (0.15) was lower than the $t_{\text {critical }}(2.22)$, showing that there was no statistically significant difference between the values.

Table 2. Results of statistical evaluation of precision for cefadroxila monohydrate capsules by spectrophotometric method.

\begin{tabular}{|c|c|c|c|c|c|c|c|c|}
\hline \multirow[b]{2}{*}{ Precision } & \multicolumn{6}{|c|}{ Results } & \multirow[b]{2}{*}{ Average } & \multirow[b]{2}{*}{$\operatorname{RSD}(\%)$} \\
\hline & 1 & 2 & 3 & 4 & 5 & 6 & & \\
\hline Intra-day & 0.594 & 0.625 & 0.627 & 0.597 & 0.627 & 0.639 & 0.618 & 2.96 \\
\hline \multirow{3}{*}{ Inter-day* } & 0.594 & 0.625 & 0.627 & 0.597 & 0.627 & 0.639 & \multirow{3}{*}{0.617} & \multirow{3}{*}{3.14} \\
\hline & 0.581 & 0.628 & 0.630 & 0.607 & 0.644 & 0.603 & & \\
\hline & 0.621 & 0.623 & 0.58 & 0.632 & 0.638 & 0.613 & & \\
\hline \multirow{2}{*}{$\begin{array}{c}\text { Between } \\
\text { analysts** }\end{array}$} & 0.621 & 0.623 & 0.580 & 0.632 & 0.638 & 0.613 & \multirow{2}{*}{0.616} & \multirow{2}{*}{2.81} \\
\hline & 0.619 & 0.618 & 0.600 & 0.627 & 0.632 & 0.593 & & \\
\hline
\end{tabular}

*ANOVA $=\mathrm{F}_{\text {calculated }} 1.52<\mathrm{F}_{\text {critical }} 3.11$

$* * \mathrm{t}_{\text {test }}($ Student $)=\mathrm{t}_{\text {calculated }} 0.29<\mathrm{t}_{\text {critical }} 2.23$

Table 3. Determination of the accuracy of the proposed spectrophotometric method.

\begin{tabular}{ccc} 
Table 3. Determination of the accuracy of the proposed spectrophotometric method. & Methods \\
\cline { 2 - 4 } Evaluation & Spectrophotometric & HPLC \\
\cline { 2 - 4 } Content determination (\%) & 98.22 & 100.59 \\
1 & 102.44 & 98.97 \\
2 & 100.32 & 100.59 \\
3 & 98.69 & 97.71 \\
4 & 100.34 & 101.92 \\
5 & 99.72 & 99.13 \\
6 & 99.95 & 99.82 \\
Average & 1.49 \\
RSD (\%) & $\mathrm{F}_{\text {calculated }} 1.01<5.05 \mathrm{~F}_{\text {critical }}$ & 1.50 \\
F-test (Snedecor) and & $\mathrm{t}_{\text {calculated }} 0.15<2.22 \mathrm{t}_{\text {critical }}$ \\
\hline -test (Student)
\end{tabular}

$\mathrm{RSD}=$ relative standard deviation 


\section{Robustness}

The robustness of the miniaturized spectrophotometric method was confirmed by the deliberate change of some parameters, shown in the Table 4. For shaking time parameter varied, the results did not robust under the conditions tested. This indicates that the method is extremely sensitive to the time that the cefadroxil is exposed in contact with the color reagent. The time exceeded for this reaction influences directly in the analytical methodology. For this reason, it is important to standardize the shaking time in 120 seconds. This was the stipulated time to occur acid-base reaction and the ratio of cefadroxil concentration and absorbance value to be linear. However, the change in wavelength to $550 \mathrm{~nm}$ and $554 \mathrm{~nm}$ had no significant impact on absorbance values $\left(\mathrm{t}_{\text {calculated }}<\mathrm{t}_{\text {critical }}\right)$ compared to the normal condition $(552 \mathrm{~nm})$. Likewise, the change in the source of water used in the preparation of the samples was also not significant $\left(\mathrm{t}_{\text {calculated }}<\mathrm{t}_{\text {critical }}\right)$.

Table 4. Evaluation of the robustness of the proposed spectrophotometric method using $t$-test (Student)

\begin{tabular}{ccccc}
\hline \multirow{2}{*}{ Parameters } & \multicolumn{2}{c}{ Condition } & \multicolumn{2}{c}{$t$-test (Student) } \\
\cline { 2 - 5 } & Normal & Modified & $t_{\text {calculated }}$ & $t_{\text {critical }}$ \\
\hline $\begin{array}{c}\text { Wavelength } \\
(\mathbf{n m})\end{array}$ & 552 & 554 & 0.22 & 2.77 \\
$\begin{array}{c}\text { Shaking time } \\
\text { (seconds) }\end{array}$ & 120 & 550 & 1.55 & 2.77 \\
Water source & MC & 180 & $9.79^{*}$ & 2.77 \\
& & 60 & $6.48^{*}$ & 2.77 \\
\end{tabular}

PC - laboratory of physical-chemical control; MC- laboratory of microbiological control; * non-robust results

\section{Discussion}

The validation of methods is essential to ensure the quality assurance of the manufactured products, making new equipment and new methods of a process to be developed with reliable and certified results [15].

Many studies are carried out on UV-visible spectrophotometric for the identification and quantification of cefadroxil [16-22], however, in none of the studies has the technique been presented in microplates, which makes the choice of the method safe to be performed and propitious for the continuity of analyzes that contribute to green analytical chemistry.

Ultraviolet and visible spectrophotometryis one of the most frequently employed technique in pharmaceutical analysis [23-29]. Absorption spectrofotometric in the ultraviolet region refers to absorption or reflectance in the visible range $(400-800 \mathrm{~nm})$ which directly affects the color of the chemicals used in the tecnique. In the region of the electromagnetic spectrum, molecules and atoms will undergo electronic transitions that will pass from the ground state to the excited state [30]. The equipment shall record in a matter of seconds the absorptivity or transmittance data obtained as a function of the wavelength.

The proposed method can be considered valid for the quantitative determination of cefadroxil monohydrate in capsules. It showed linearity in the range of 15 to $115 \mu \mathrm{g}$ $\mathrm{mL}^{-1}$; selectivity when comparing standard, sample, adjuvants and color reagent; precision with deviations below $4 \%$; accuracy when comparing the proposed method with the HPLC method; robustness by making small and deliberate modifications to the method. It is also an ecologically correct method, easy to handle, fast, low cost, does not use organic solventes, does not need sample pretreatment and the waste generation is minimal. These characteristics include it in the current and sustainable green analytical chemistry for the analysis of pharmaceutical products.

\section{Conclusions}

For the first time, a miniaturized spectrophotometric method was validated for the determination of the cefadroxil monohydrate in capsules. The method was selective, linear, precise, accurate and robust. It contributes to green analytical chemistry, since it is fast, low cost, reliable, does not use organic solvents, waste generation is minimal, being an eco-friendly alternative to the routine analyzes of quality control of this pharmaceutical product. syndromes.

\section{Acknowledgements}

The authors acknowledge CNPq (Brasília, Brazil), FAPESP (São Paulo, Brazil) and CAPES (São Paulo, Brazil).

\section{Conflict of interest}

The authors declare no conflicts of interest

\section{References}

1. Devaliya R, Jain UK. Noval estimation of cefadroxil in tablet dosage forms by RP-HPLC. Ori J Chem 2009; 25:1053-1058.

2. Dey S, Kalyani K, Samyuktha B, Sahoo SK, Mohapatra S, Murthy PN, Kumar D. Development and validation of a $\mathrm{UV}-\mathrm{Vis}$ spectrophotometric method for the estimation and degradation monitoring of cefadroxil in bulk and pharmaceutical dosage forms. Int J Chem Res 2010; 1:2934.

3. Jain MS, Bavaskar SR, Barhate SD, Fegade JD. Simultaneous UV spectrophotometric methods for estimation of cefadroxil and probencid in tablet dosage form. Ind J Pharm Sci Res 2014; 4:18-21.

4. Nagarajan JSK, Vimal CS, George R, Dubala A. Simultaneous pharmacokinetic assessment of cefadroxil and clavulanic acid in human plasma by LC-MS and its application to bioequivalence studies. J Pharm Anal 2013; 3:285-291. 
5. Pradip D, Santosh J, Sumit G, Laxmi J. Development and validation of UV spectrophotometric estimation of cefadroxil in bulk and tablet dosage form using area under curve method. Indu Amer J Pharm Sci 2015; 2:581-586.

6. Rao KG, Shankar BU, Phanindra B, Naik $M$. Development and validation of RP-HPLC method for the estimation of cefadroxil monohydrate in bulk and its tablete dosage form. J Advance Pharmacy Educ Res 2014; 4:71-74.

7. Sharif SI, Khan U, Ashfaq M, Iqbal MS, Ahmad S. Development and validation of high performance liquid chromatographic method for the simultaneous determination of potassium clavulanate and cefadroxil in synthetically prepared tablets. J Anal Chem 2010; 65:1053-1058.

8. U.S. Pharmacopeia. 39th Ed., United States Convention Inc., Rockville, MD 2016.

9. Fiol FSD, Lopes LC, Toledo ML, Barberato-Filho S. Profile of prescriptions and use of antibiotics in community infections. J Braz Soc Trop Med 2010; 43:68-72.

10. Nicolini P, Nascimento JWL, Greco KV, Menezes FG. Factors related to the medical prescription of antibiotics in public pharmacy in the western region of the city of São Paulo. Sci Coll Health 2008; 13:689-696.

11. Marco BA; Salgado HRN. Characteristics, properties and analytical methods of cefadroxil: a review. Crit Rev Anal Chem 2017; 47:93-98.

12. International Conference on Harmonization. ICH Guidance for Industry Q2(R1), Validation of analytical procedures: Text and Methodology, 2005. https://www.ich.org/fileadmin/Public_Web_Site/ICH_Produ cts/Guidelines/Quality/Q2_R1/Step4/Q2_R1__Guideline.pd $\mathrm{f}$

13. Food and Drug Administration. FDA Center for drug evaluation and research, Guidance Industry: Bioanalytical Method Validation, 2013. https://www.fda.gov/downloads/drugs/guidances/ucm07010 7.Pdf

14. Marco BA, Salgado HRN. Development and validation of a green RP-HPLC method for quantification of cefadroxil capsules. World J Pharm Pharm Sci 2017; 6:2074-2091.

15. Marco BA, Salgado HRN. Development and validation of an innovative method for the determination of cefadroxil monohydrate in capsules. Phys Chem 2016; 6:67-74.

16. Saleh GA, Askal HF, Radwan MF, Omar MA. Use of charge-transfer complexation in the spectrophotometric analysis of certain cephalosporins. Talanta 2001; 54:12051215 .

17. Thabit S, Al-Ghabsha N, Subhi M. Spectrophotometric determination of cephradine and cefadroxil using 2,3dichloro-5,6-dicyano-1,4-benzoquinone reagent. J Pure Appl Sci 2007; 4:13-28.
18. Ali SM, Elbashir AA. Development and validation of spectrophotometric method for the determination of cefadroxile and cefuroxime sodium in pharmaceutical formulations via derivitization with 8-hydroxy-1, 3,6pyrenesulfonic acid trisodium. Asian J Pharm Technol Innov 2013; 2:1-12.

19. Rageh AH, Elshaboury SR, Saleh GA, Mohamed FA. Spectophotometric method for determination of certain cephalosporins using 4-chloro-7-nitrobenzo-2-oxa-1, 3diazole (NBD-Cl). Natural Sci 2010; 2:828-840.

21. El-Ansary A, Abdel-Gawad FM, Badawy SS, Ibrahim MMJ. Spectrophotometric determination of some cephalosporins using palladium(II) chloride. Drug Res 2004; 25:7-12.

22. Hassan M, Abeed FA, Saif BA. A new kinetic spectrophotometric method for determination of cefadroxil in pharmacetical formulation using Lawsonia inermis (Henna) as natural reagent. Anal Bioanal Chem 2014; 4:116-128.

23. Kogawa AC, Salgado HRN. Quantification of doxycycline hyclate in tablets by ultraviolet spectrophotometric method. WJPR 2013; 1:21-24.

24. Kogawa AC, Salgado HRN. Quantification of rifaximin in tablets by spectrophotometric method ecofriendly in ultraviolet region. Scientifica 2016; 2016:1-9.

25. Brbaklic V, Kogawa AC, Salgado HRN. Quantification of rifaximin in tablets by an environmentally friendly visible spectrophotometric method. Curr Pharm Anal 2017; 13:532537.

26. Alessio PV, Kogawa AC, Salgado HRN. Quality of ceftriaxone sodium in lyophilized powder for injection evaluated by clean, fast, and efficient spectrophotometric method. J Anal Methods Chem 2017; 2017:1-4.

27. Rechelo BS, Fernandes FHA, Kogawa AC, Salgado HRN. New environmentally friendly method for quantification of cefazolin sodium. Eur Chem Bull 2017; 6:238-245.

28. Kogawa AC, Salgado HRN. Rifaximin in tablets: is it possible to evaluate the quality by UV, IR, CE, HPLC and turbidimetric methods? EC Microbiology 2018; 14:16-20.

29. Souza MJM, Kogawa AC, Salgado HRN. New and miniaturized method for analysis of enrofloxacin in palatable tablets. Spectrochim. Acta A 2019; 209:1-7.

30. Ali SM, Elbashir AA, Aboul-Enein HY. Spectroscopic methods for analysis of cephalosporins in pharmaceutical formulations. World J Anal Chem 2015; 3:21-32. 